\title{
Initial adherence by psychiatric outpatients in a general hospital and relevant personal factors
}

Minhua Chen ${ }^{1 \dagger}$, Lina Zhou ${ }^{1 \dagger}$, Li Ye ${ }^{1}$, Gelin Lin ${ }^{1}$, Yongli Pang ${ }^{1}$, Liyun Lu ${ }^{1}$ and Xianglan Wang ${ }^{2 *}$

\begin{abstract}
Background: Initial adherence is a predictor of long-term adherence and thus is a crucial metric to explore and support. This study aimed to investigate initial adherence by psychiatric outpatients and relevant personal factors.

Methods: The study surveyed psychiatric outpatients using a 30-day timely return visit rate (TRVR) after the first visit to indicate initial adherence. All participants agreed to engage in the self-designed survey and assessments of the Eysenck Personality Questionnaire (EPQ) and Symptoms Checklist-90 (SCL-90). Clients who missed timely return visits received telephone follow-up to determine the main reasons.

Results: The overall TRVR was 59.4 , and $40.6 \%$ of clients missed return visits. Logistic regression analysis revealed risk factors for initial adherence were work, tense family atmosphere, negative attitudes towards medication, higher EPQ psychoticism score, and lower SCL-90 phobic anxiety score. The main reasons given for non-timely return visits were improvement suggesting lack of need for a return visit, various barriers, no improvement, and side effects.
\end{abstract}

Conclusion: Psychiatric outpatients had poor initial adherence related to multiple dimensional factors, including job, family, personality characteristics, mental status, and thoughts about mental illness and treatments.

Keywords: Psychiatric outpatients, Adherence, Return visit, Pharmacotherapy

\section{Background}

Adherence is an assessment indicator of a patient's illness behavior, referring to the extent to which the patient adopts behavior consistent with a treatment plan negotiated by the doctor and patient [1]. The International Society for Pharmacoeconomics and Outcomes Research proposed two types of medical adherence: initial (IMA) and long-term (LTA). IMA refers to adherence after being prescribed a new drug, and LTA refers to adherence during continuous medication or long-term treatment $[2,3]$. Poor IMA can predicate worse LTA [4].

*Correspondence: wxiangl@mail.sysu.edu.cn

${ }^{\dagger}$ Minhua Chen and Lina Zhou contributed equally to this work.

2 Department of Psychiatry, Fifth Affiliated Hospital of Sun Yat-sen

University, N0. 52, East Meihua Road, Zhuhai 519000, China

Full list of author information is available at the end of the article
Currently, there is no consistent definition of the "initial" phase with most studies defining it as 14 to 28 days after a new prescription or the first visit but others including periods of months or even a year [2]. At the same time, initial adherence is a more widely concept describing illness behavior than IMA. Thus, this study defined the initial phase as 30 days after the first visit and used timely return visit (TRV) behavior as the outcome indicator of initial adherence.

Poor adherence is a global challenge for psychiatric clinical practices [5]. High proportions of psychiatric patients have shown poor treatment adherence, leading to poor treatment outcomes and resulting in a massive waste of social resources [4, 6-10]. Factors found to impact treatment adherence among psychiatric patients are cognitive responses, patients' trust in 
doctors, patients' perception of their mental health, and age, unpleasant side effects of drugs, attitudes towards drugs, paranoia symptoms, substance abuse, self-knowledge, and family environment $[11,12]$. There was a rare study on the relationship between personality traits and adherence. A preliminary study showed that psychiatric patients with irritable affective temperament might have poor treatment adherence [13]. However, a pilot study did not find the relationship between personality traits and adherence to antidepressants assessed through selfreporting and electronic monitoring [14].

Most previous studies have focused on long-term medication adherence. The initial adherence in psychiatric outpatients and its relevant factors remain unclear. Thus, the present study investigated the initial adherence in a large sample and performed a telephone follow-up in clients with poor adherence. This study focused on the profile of the initial adherence by psychiatric outpatients and its relevant personal factors. It was assumed that initial adherence was relevant to multiple psychosocial factors, including demographic data, family environment, incoming level, attitudes towards pharmacotherapy, primary diagnosis, symptoms profile, and personality characteristics. Generally, personality traits influence behavioral patterns, and therefore this study assumed they could affect illness behavior such as initial adherence. The telephone survey on reasons for non-timely return visits would much enrich understanding of non-adherence behavior. The findings of this study could provide meaningful evidence for practical efforts to improve initial adherence in psychiatric outpatients.

\section{Methods}

\section{Participants}

All participants were first-visit clients of the psychiatric outpatient department of the Third Affiliated Hospital of Sun Yat-sen University from May to October 2018. The inclusion criteria were as follows: (1) provided informed consent, (2) age between 18 and 65 years, (3) education level above primary school, (4) doctors prescribed medicine at the first visit, and (5) provided complete data. Patients hospitalized after the first visit were excluded. This study was in line with the Declaration of Helsinki, Ethical Principles for Medical Research Involving Human Subjects (World Medical Association, 2013 )[15].

\section{Survey and Instruments \\ First-visit questionnaire}

This self-designed questionnaire was used to investigate age, gender, education level, marital status, employment status, monthly income, residence, family atmosphere, living status, and attitudes towards pharmacotherapy.
The respondents completed this survey on their first visit according to their actual circumstances.

\section{Timely return visit (TRV)}

Based on the hospital information system records, TRV refers to a client completing at least one return visit within 30 days after the first visit; otherwise, the patient was labeled "non-timely return visit" (NTRV). TRV rate $(\mathrm{TRVR})=\mathrm{TRV}$ cases number / total sample number $\times 100 \%$. This study used TRVR as the indicator of initial adherence.

\section{Eysenck Personality Questionnaire (EPQ) Chinese version}

The EPQ has been widely used to evaluate personality characteristics in China since it was translated into Chinese and standardized in the 1980s [16]. It includes 88 items and four subscales: Psychoticism (P), Extraversion (E), Neuroticism (N), and Lie (L) [17].

\section{Symptom checklist 90 (SCL-90) Chinese version}

The SCL-90 is usually used to assess mental health [18, 19]. It comprises 90 items and 10 subscales to assess somatization, obsessive-compulsiveness, interpersonal sensitivity, depression, anxiety, hostility, phobic anxiety, paranoid ideation, psychoticism, and additional status (mainly including sleep and eating conditions) [20].

\section{Telephone follow-up questionnaire}

This questionnaire was self-designed by the researchers. It listed various presupposed reasons for NTRVs: patients' refusal, unsatisfactory effects, unsatisfactory outpatient environment, improvement leading to believe there is no further need for a return visit, fear of side effects, significant side effects, no time, far distance, failure to make an appointment, economic problems, and others. According to their actual conditions, the respondents could choose one presupposed reason or supply a specific other reason on the telephone.

\section{Statistic analysis}

The dataset was built via SPSS 25.0. Descriptive statistics were used in distributions of the TRVR and reasons for NTRVs. Group comparisons of numerical data such as EPQ and SCL-90 subscale scores were analyzed via an independent t-test. Group comparisons for category data such as age group, marital status, monthly income, and residence were made via $\chi^{2}$ test. The relevant factors for the NTRV were analyzed using Wald forward binary logistic regression. The significance level was set at $\alpha=0.05$ except for the significance level of $\alpha=0.1$ for selecting independent variables to enroll all potentially relevant factors in the regression process. 


\section{Results}

\section{Investigation into the TRVR and its relevant factors} Overall TRVR

In total, 2843 cases meeting inclusion criteria entered statistical analysis, and 1689 completed at least one return visit 30 days after the first visit. The overall TRVR was $59.4 \%$, and 1154 cases (40.6\%) missed the TRV (34.2\% in patients with psychotic disorders). Thus, participants were divided into two groups: TRV $(n=1689)$ and NTRV $(n=1154)$.

\section{Demographic data}

Table 1 shows the participants' demographic data and the TRVR distribution among subgroups. There were statistically significant TRVR differences among age, job status, and residence subgroups. Regarding the age groups, the TRVR was highest for the 46-55-year-old subgroup $(66.8 \%)$ and lowest for the 26-35-year-old subgroup (55.3\%) $\left(\chi^{2}=15.409, P=0.004\right)$. The TRVR of the on-the-job subgroup was $56.2 \%$, which was significantly higher than that of students or no-job subgroups $\left(\chi^{2}=16.297, P<0.001\right)$. The rural residence subgroup had a higher TRVR (63.2\%) than the urban residence subgroup (58.2\%) $\left(\chi^{2}=10.243, P=0.017\right)$.

\section{Family atmosphere and living status}

Table 1 also lists the TRVR distributions related to family atmosphere and living status. Participants with a worse family atmosphere had the lowest TRVR (53.9\%), and those with a happy atmosphere had the highest (64.9\%) $\left(X^{2}=10.677, P=0.014\right)$. Participants living with family members had a higher TRVR (61.1\%) than those living with a lover or alone $\left(\chi^{2}=8.962, P=0.011\right)$.

\section{Mean EPQ and SCL-90 factor scores}

As shown in Table 2, there were no significant differences in mean factor scores of Extraversion, Neuroticism, Psychoticism, and Lie on the EPQ between the TRV and NTRV groups. The TRV group had significantly higher mean factor scores of SCL-90 Somatization ( $2.05 \pm 0.78$ vs. $1.99 \pm 0.80, P=0.04)$, Anxiety $(2.60 \pm 0.93$ vs. $2.52 \pm 0.95, P=0.026)$, and Phobic anxiety $(2.02 \pm 0.84$ vs. $1.93 \pm 0.84, P=0.009)$ than the NTRV group.

\section{Attitudes towards pharmacotherapy and diagnoses}

Attitudes towards pharmacotherapy might influence TRVR. Patients willing to receive pharmacotherapy had the highest TRVR (65.1\%), and those refusing pharmacotherapy had the lowest (44.2\%). The TRVR differences among subgroups of attitudes towards medicine were significant $\left(\chi^{2}=50.807, P<0.001\right)$. Regarding the primary diagnosis, patients with psychotic and bipolar disorder had the two highest TRVRs of 65.8 and $61.8 \%$, respectively, and those with sleep disorders had the lowest (51.1\%). However, the TRVR differences among patients with primary diagnoses were not significant $(P=0.444)$. See Table 1 .

\section{Logistic regression model of the NTRV}

Let return visit status $(0-$ TRV, 1 - NTRV) be the dependent variable and significant variables $(\alpha=0.1)$ related to TRVR in the above statistics such as age groups, working status, residence, family atmosphere, living status, attitudes towards pharmacotherapy, EPQ psychoticism score, and SCL-90 subscale scores of somatization, anxiety, and phobic anxiety be independent variables. The result of the stepwise forward binary logistic regression showed that variables of age groups, working status, family atmosphere, attitudes towards pharmacotherapy, psychoticism score, and phobic anxiety score entered the regression model $\left(\chi^{2}=99.060, d f=14, P<0.001\right.$; overall predicted percentage correct $=61.5 \%)$. People aged $46-55$ years $(O R=0.674$, $P=0.007$, reference to age $18-25$ years) with higher SCL-90 phobic anxiety scores $(O R=0.851, P=0.001)$ were at lower risk for NTRV. People with worse $(O R=1.540, P=0.008)$ or relaxed family atmosphere $(O R=1.364, P=0.008$, reference to happy family atmosphere), attitudes towards pharmacotherapy of refusing medicine $(O R=2.265, P<0.001)$, fear of side effects $(O R=1.950, P<0.001$, reference to being willing to pharmacotherapy), on the job $(O R=1.328$, $P=0.004$, reference to housework or no-job), and higher EPQ psychoticism scores $(O R=1.008, P=0.049)$ were at higher risk for NTRV. See Table 3.

\section{Investigation of reasons for NTRV via telephone follow-up The profile of telephone follow-up}

Among 1154 clients with NTRVs after the first interview, 693 (60.1\%) accepted the telephone investigation, and 461 cases $(39.9 \%)$ did not. Conditions of follow-up failure included 333 clients (72.2\%) that rejected calls, $98(21.3 \%)$ that provided the wrong telephone numbers at the first visit, and $30(6.5 \%)$ that answered the call but refused the investigation.

\section{Conditions after the first interview}

Among 693 cases in which the investigation was completed, 473 (68.4\%) clients continued taking medicines according to the prescription (128 of these accepted the advice of return visit as soon as possible, and 346 refused this advice), 73 (10.5\%) had continued to visit other hospitals, and 146 (21.1\%) had stopped taking medicine and abandoned treatment. 
Table 1 General data, attitudes towards pharmacotherapy, primary diagnosis, and distributions of TRVR (N, \%)

\begin{tabular}{|c|c|c|c|c|c|}
\hline & $\mathrm{N}, \%$ & TRV & NTRV & $x^{2}$ & $P$-value \\
\hline Gender & & & & 0.091 & 0.763 \\
\hline Male & $1165,41.0$ & $696,59.7$ & $469,40.3$ & & \\
\hline Female & $1678,59.0$ & $993,59.2$ & $685,40.8$ & & \\
\hline Age group & & & & 15.409 & 0.004 \\
\hline $18 \sim 25$ years & $1056,37.1$ & $630,59.7$ & $426,40.3$ & & \\
\hline $26 \sim 35$ years & $823,28.9$ & $455,55.3$ & $368,44.7$ & & \\
\hline $36 \sim 45$ years & $473,16.6$ & $279,59.0$ & $194,41.0$ & & \\
\hline $46 \sim 55$ years & $358,12.6$ & $239,66.8$ & $119,33.2$ & & \\
\hline $56 \sim 65$ years & $133,4.7$ & $86,64.7$ & $47,35.3$ & & \\
\hline Educational stage & & & & 4.240 & 0.237 \\
\hline Primary school & $158,5.6$ & $101,63.9$ & $57,36.1$ & & \\
\hline Junior high school & $458,16.1$ & $280,61.1$ & $178,38.9$ & & \\
\hline Senior high school or equivalent & $567,19.9$ & $347,61.2$ & $220,38.8$ & & \\
\hline College and higher & $1660,58.4$ & $961,57.9$ & $699,42.1$ & & \\
\hline Marital status & & & & 2.721 & 0.437 \\
\hline Unmarried & $1368,48.1$ & $816,59.6$ & $552,40.4$ & & \\
\hline Married & $1355,47.7$ & $802,59.2$ & $553,40.8$ & & \\
\hline Divorced & $103,3.6$ & $64,62.1$ & $39,37.9$ & & \\
\hline Widowed & $17,0.6$ & $7,41.2$ & $10,58.8$ & & \\
\hline Work status & & & & 16.297 & $<0.001$ \\
\hline Work & $1616,56.8$ & $908,56.2$ & $708,43.8$ & & \\
\hline Student & $562,19.8$ & $354,63.0$ & $208,37.0$ & & \\
\hline Housework or workless & $665,23.4$ & $427,64.2$ & $238,35.8$ & & \\
\hline Monthly income in RMB & & & & 3.900 & 0.272 \\
\hline$<5$ thousands & $685,24.1$ & $412,60.1$ & $273,39.9$ & & \\
\hline $5 \sim 10$ thousands & $1095,38.5$ & $668,61.0$ & $427,39.0$ & & \\
\hline $10 \sim 30$ thousands & $774,27.2$ & $449,58.0$ & $325,42.0$ & & \\
\hline$>30$ thousands & $289,10.2$ & $160,55.4$ & $129,44.6$ & & \\
\hline Residence & & & & 10.243 & 0.017 \\
\hline Urban & $2138,75.2$ & $1244,58.2$ & $894,41.8$ & & \\
\hline Rural & $705,24.8$ & $445,63.2$ & $260,36.9$ & & \\
\hline Family atmosphere & & & & 10.677 & 0.014 \\
\hline Happy & $498,17.5$ & $323,64.9$ & $175,35.1$ & & \\
\hline Relaxed & $900,31.7$ & $518,57.6$ & $382,42.4$ & & \\
\hline Tense & $1189,41.8$ & $710,59.7$ & $479,40.3$ & & \\
\hline Worse & $256,9.0$ & $138,53.9$ & $118,46.1$ & & \\
\hline Living status & & & & 8.962 & 0.011 \\
\hline With family members & $1917,67.4$ & $1171,61.1$ & $746,38.9$ & & \\
\hline With a lover & $165,5.8$ & $84,50.9$ & $81,49.1$ & & \\
\hline Alone & $761,26.8$ & $434,57.0$ & $327,43.0$ & & \\
\hline Attitudes towards pharmacotherapy & & & & 50.807 & $<0.001$ \\
\hline Willing & $387,13.6$ & $252,65.1$ & $135,34.9$ & & \\
\hline Could accept if necessary & $1856,65.3$ & $1155,62.2$ & $701,37.8$ & & \\
\hline Afraid of side effects & $374,13.2$ & $182,48.7$ & $192,51.3$ & & \\
\hline Refusing & $226,7.9$ & $100,44.2$ & $126,55.8$ & & \\
\hline Primary diagnoses & & & & 6.858 & 0.444 \\
\hline Consultation or observation & $239,8.4$ & $143,59.8$ & $96,40.2$ & & \\
\hline Depression & $1257,44.2$ & $738,58.7$ & $519,41.3$ & & \\
\hline Anxiety & $624,21.9$ & $380,60.9$ & $244,39.1$ & & \\
\hline Bipolar disorder & $288,10.1$ & $178,61.8$ & $110,38.2$ & & \\
\hline Psychotic disorders & $73,2.6$ & $48,65.8$ & $25,34.2$ & & \\
\hline Sleep disorders & $141,5.0$ & $72,51.1$ & $69,48.3$ & & \\
\hline Obsessive-compulsion & $54,1.9$ & $32,59.3$ & $22,40.7$ & & \\
\hline Others & $167,5.9$ & $98,58.7$ & $69,41.3$ & & \\
\hline
\end{tabular}

TRVR: timely return visit rate; TRV: timely return visit; NTRV: non-timely return visit 
Table 2 Comparisons of EPQ and SCL-90 scores between the timely and non-timely return visit groups $(\mathrm{M} \pm \mathrm{SD})$

\begin{tabular}{|c|c|c|c|c|}
\hline & TRV & NTRV & $t$ & $P$-value \\
\hline \multicolumn{5}{|l|}{ EPQ } \\
\hline Psychoticism & $53.88 \pm 10.19$ & $54.53 \pm 10.61$ & -1.662 & 0.097 \\
\hline Extraversion & $47.43 \pm 11.04$ & $47.95 \pm 11.45$ & -1.208 & 0.227 \\
\hline Neuroticism & $60.36 \pm 11.72$ & $59.73 \pm 12.23$ & 1.402 & 0.639 \\
\hline Lie & $46.49 \pm 10.44$ & $46.83 \pm 10.24$ & -0.870 & 0.384 \\
\hline \multicolumn{5}{|l|}{ SCL-90 } \\
\hline Somatization & $2.05 \pm 0.78$ & $1.99 \pm 0.80$ & 2.053 & 0.040 \\
\hline $\begin{array}{l}\text { Obsessive-com- } \\
\text { pulsive }\end{array}$ & $2.59 \pm 0.88$ & $2.55 \pm 0.89$ & 1.302 & 0.193 \\
\hline $\begin{array}{l}\text { Interpersonal } \\
\text { sensitivity }\end{array}$ & $2.31 \pm 0.92$ & $2.29 \pm 0.93$ & 0.477 & 0.633 \\
\hline Depression & $2.68 \pm 0.96$ & $2.65 \pm 0.98$ & 0.781 & 0.435 \\
\hline Anxiety & $2.60 \pm 0.93$ & $2.52 \pm 0.95$ & 2.234 & 0.026 \\
\hline Hostility & $2.23 \pm 0.91$ & $2.27 \pm 0.94$ & -1.364 & 0.173 \\
\hline Phobic anxiety & $2.02 \pm 0.84$ & $1.93 \pm 0.84$ & 2.631 & 0.009 \\
\hline Paranoid ideation & $2.07 \pm 0.89$ & $2.07 \pm 0.89$ & -0.132 & 0.895 \\
\hline Psychoticism & $2.13 \pm 0.80$ & $2.11 \pm 0.82$ & 0.628 & 0.530 \\
\hline Additional items & $2.54 \pm 0.82$ & $2.48 \pm 0.83$ & 1.919 & 0.055 \\
\hline
\end{tabular}

TRV timely return visit, NTRV non-timely return visit, SCL-90 symptoms checklist-90, EPQ Eysenck Personality Questionnaire

\section{Self-reported reasons for NTRVs}

According to respondents' answers, the main reasons for NTRVs were as follows: 383 (55.3\%) considered the return visit unnecessary because they felt better, 87 (12.6\%) felt no improvement, 60 (8.7\%) felt noticeable side effects of the medicine, $20(2.9 \%)$ were afraid of side effects of the medicine, 51 (7.4\%) reported inconvenience of traveling to the hospital, 61 (8.8\%) had no time, 24 (3.5\%) failed to make appointments, 4 (0.6\%) reported rejecting the return visit, $1(0.1 \%)$ acknowledged difficult economic circumstances, and $2(0.3 \%)$ were unsatisfied with the hospital environment. These reasons were merged and divided into four groups to meet the statistical conditions: improvement and consideration of no need for a return visit (55.3\%), no improvement (12.6\%), side effects of medicines (11.5\%), and various barriers (20.6\%). The distribution of self-reported reasons for the NTRV differed significantly among 4 conditions after the first interview $\left(\chi^{2}=221.989, P<0.001\right)$. See Table 4 .

\section{Self-reported reasons for NTRV among varied diagnoses}

Table 5 shows self-reported reasons for NTRVs from respondents with different primary diagnoses. Distributions of self-reported reasons for NTRVs of patients with bipolar disorders were similar to that of psychotic disorders, and so as anxiety disorders to obsessive-compulsive disorder (OCD). So we merged data of bipolar disorder and psychotic disorders, anxiety disorders and OCD, respectively, to meet the statistical need. As to reasons for NTRVs, except the diagnosis classification of "others", patients with sleep disorder (16.3\%) and anxiety/OCD (16.1\%) reported higher rates of "no improvements" than other diagnosis classifications, especially bipolar disorder/psychotic disorders (8.0\%) and consultation or observation (5.7\%). Patients with sleep disorder also reported the highest "barriers" rate (32.6\%) among all diagnoses. Patients with bipolar disorder/psychotic disorders (13.6\%) and depression (12.5\%) reported higher rates of "medicine side effects" than other diagnoses, especially sleep disorder (7.0\%). However, the $\chi^{2}$ test result showed that the differences above were insignificant $\left(\chi^{2}=17.829\right.$, $P=0.272$ ).

\section{Discussion}

The present study focused on the initial adherence of psychiatric outpatient first-visit clients in a relatively large sample. We used TRVR as the indicator of the initial adherence and found an overall TRVR of $59.4 \%$ as well as its multiple relevant factors, such as attitude towards medication, family atmosphere, working status, age, and EPQ psychoticism and SCL-90 phobic anxiety subscale scores. From the clients' perspective, through a telephone follow-up, we found that the main reasons for the NTRV included considering return visits unnecessary because of improvement and other various barriers.

Poor initial adherence could decrease the probability of receiving normative and professional treatment, impair outcomes, and even lead to severe consequences [5]. However, poor initial adherence remains a global challenge for psychiatric practices [3, 21]. Ibironke et al. reported a prevalence of $30 \%$ of missed first appointments 2-3 weeks after the first outpatient visit in patients with schizophrenia [8]. According to National Comorbidity Survey Replication data, the mental health treatment dropout rate from the general medication sector at 12 months was $31.6 \%$, and over $70 \%$ of all dropouts occurred after the first or second visit [22]. A systematic review published in 2021 mentioned that non-adherence ranged between 63 and $74 \%$ in patients with schizophrenia and about $50 \%$ in patients with bipolar disorder [23]. In Chinese, Yau et al. reported a non-continuous use of antidepressant prevalence of $46 \%$ among 189 patients in Hongkong with major depressive disorder newly prescribed antidepressant [24]. Gu et al. investigated the medication adherence within 30 days after the first treatment in 150 first-onset depression outpatients in China mainland and found a poor adherence prevalence of $53.3 \%(80 / 150)$ [25]. Our findings of high nonadherence prevalence of $40.6 \%$ in psychiatric outpatients and $34.2 \%$ 
Table 3 Logistic regression model of the non-timely return visit

\begin{tabular}{|c|c|c|c|c|c|c|c|c|}
\hline & \multirow[t]{2}{*}{$B$} & \multirow[t]{2}{*}{ S.E. } & \multirow[t]{2}{*}{ Wald } & \multirow[t]{2}{*}{$d f$} & \multirow[t]{2}{*}{$P$-value } & \multirow[t]{2}{*}{$\operatorname{Exp}(B)$} & \multicolumn{2}{|c|}{ 95\% C.I. for $\operatorname{EXP}(B)$} \\
\hline & & & & & & & Lower & Upper \\
\hline Age groups & & & 10.792 & 4 & 0.029 & & & \\
\hline $18 \sim 25$ years & & & Ref. & & & & & \\
\hline $26 \sim 35$ years & 0.022 & 0.114 & 0.038 & 1 & 0.846 & 1.022 & 0.818 & 1.278 \\
\hline $36 \sim 45$ years & -0.126 & 0.131 & 0.922 & 1 & 0.337 & 0.882 & 0.682 & 1.140 \\
\hline $46 \sim 55$ years & -0.394 & 0.146 & 7.301 & 1 & 0.007 & 0.674 & 0.506 & 0.897 \\
\hline $56 \sim 65$ years & -0.209 & 0.207 & 1.025 & 1 & 0.311 & 0.811 & 0.541 & 1.217 \\
\hline Family atmosphere & & & 9.452 & 3 & 0.024 & & & \\
\hline Happy & & & Ref. & & & & & \\
\hline Relax & 0.310 & 0.118 & 6.935 & 1 & 0.008 & 1.364 & 1.083 & 1.719 \\
\hline Tense & 0.219 & 0.115 & 3.653 & 1 & 0.056 & 1.245 & 0.994 & 1.558 \\
\hline Worse & 0.432 & 0.164 & 6.928 & 1 & 0.008 & 1.540 & 1.117 & 2.123 \\
\hline Attitude towards pharmacotherapy & & & 45.289 & 3 & $<0.001$ & & & \\
\hline Willing & & & Ref. & & & & & \\
\hline Could accept if necessary & 0.120 & 0.119 & 1.030 & 1 & 0.310 & 1.128 & 0.894 & 1.423 \\
\hline Afraid of side effects & 0.668 & 0.152 & 19.377 & 1 & $<0.001$ & 1.950 & 1.449 & 2.626 \\
\hline Refusing pharmacotherapy & 0.818 & 0.174 & 22.014 & 1 & $<0.001$ & 2.265 & 1.610 & 3.187 \\
\hline Working status & & & 13.270 & 2 & 0.001 & & & \\
\hline On the job & 0.283 & 0.098 & 8.326 & 1 & 0.004 & 1.328 & 1.095 & 1.610 \\
\hline Student & -0.074 & 0.141 & 0.277 & 1 & 0.599 & 0.928 & 0.704 & 1.224 \\
\hline Housework or no job & & & Ref. & & & & & \\
\hline SCL-90 Phobic anxiety score & -0.162 & 0.049 & 10.827 & 1 & 0.001 & 0.851 & 0.773 & 0.937 \\
\hline EPQ Psychoticism & 0.008 & 0.004 & 3.886 & 1 & 0.049 & 1.008 & 1.000 & 1.015 \\
\hline Constant & -1.019 & 0.284 & 12.918 & 1 & $<0.001$ & 0.361 & & \\
\hline
\end{tabular}

Ref the reference category of the variable, SCL-90: symptoms checklist-90; EPQ: Eysenck Personality Questionnaire

Table 4 The distribution of reasons for non-timely return visit among conditions after the first interview

\begin{tabular}{lllllll}
\hline Conditions & $\boldsymbol{N}, \%$ & \multicolumn{2}{l}{ Self-reported reasons $(\boldsymbol{N}, \%)$} & $X^{2}$ & \\
\cline { 2 - 5 } & & $\mathbf{A}(\boldsymbol{n}=\mathbf{8 7})$ & $\mathbf{B}(\boldsymbol{n}=\mathbf{3 8 3})$ & $\mathbf{C}(\boldsymbol{n}=\mathbf{8 0})$ & $\mathbf{D}(\boldsymbol{n}=\mathbf{1 4 3 )}$ & \\
\hline I & $128,18.5$ & $9,7.0$ & $60,46.9$ & $11,8.6$ & $48,37.5$ & 221.989 \\
II & $346,49.9$ & $28,8.1$ & $239,69.1$ & $22,6.4$ & $57,16.5$ & $<0.001$ \\
III & $73,10.5$ & $34,46.6$ & $7,9.6$ & $3,4.1$ & $29,39.7$ & \\
IV & $146,21.1$ & $16,11.0$ & $77,52.7$ & $44,30.1$ & $9,6.2$ & \\
\hline
\end{tabular}

Self-reported reasons: A: No improvement; B: Improvement and belief there is no need for a return visit; C: Medicine side effects; D: Barriers

Conditions: I: Taking medicine and accepting to complete a return visit; II: Taking medicine and unwilling to complete a return visit; Ill: Transferred to another hospital; IV: Treatment abandonment

in patients with psychotic disorders 30 days after the first visit were consistent with the previous studies. They all supported the determination that it is time to pay more attention to and effectively improve initial adherence in psychiatric outpatients.

Generally, initial adherence was among the illness behaviors critically influenced by cognitive appraisal and decision-making by patients based on their perceived information from illness and appropriate treatment acknowledge, feelings related to self-distress, doctor interview, effects, side effects, and balancing benefits against costs [26, 27].

Attitude towards medication markedly influenced initial adherence. People with negative attitudes towards pharmacotherapy had the worst TRVR of $44.2 \%$ (Table 1), and refusal of medicine was a key predictor with the highest $O R$ of 2.265 to the poor initial adherence (Table 3). At the same time, regarding the 
Table 5 The distribution differences of self-reported reasons for non-timely return visit among primary diagnoses

\begin{tabular}{|c|c|c|c|c|c|c|c|}
\hline \multirow[t]{2}{*}{ Diagnoses } & \multirow[t]{2}{*}{$N, \%$} & \multicolumn{4}{|c|}{ Self-reported reasons $(N, \%)$} & \multirow[t]{2}{*}{$x^{2}$} & \multirow[t]{2}{*}{$P$-value } \\
\hline & & A $(n=87)$ & $\mathrm{B}(n=383)$ & $C(n=80)$ & $\mathrm{D}(n=143)$ & & \\
\hline Consultation or observation & $53,7.6$ & $3,5.7$ & $33,62.3$ & $5,9.4$ & $12,22.6$ & 17.829 & 0.272 \\
\hline Depression & $305,44.0$ & $34,11.1$ & $175,57.4$ & $38,12.5$ & $58,19.0$ & & \\
\hline Anxiety/OCD & $161,23.2$ & $26,16.1$ & $85,52.8$ & $18,11.2$ & $32,19.9$ & & \\
\hline Bipolar disorder/Psychotic disorders & $88,12.7$ & $7,8.0$ & $51,58.0$ & $12,13.6$ & $18,20.5$ & & \\
\hline Sleep disorder & $43,6.2$ & $7,16.3$ & $19,44.2$ & $3,7.0$ & $14,32.6$ & & \\
\hline others & $43,6.2$ & $10,23.3$ & $20,46.5$ & $4,9.3$ & $9,20.9$ & & \\
\hline
\end{tabular}

Self-reported reasons: A: No improvement; B: Improvement and belief there is no need for a return visit; C: Medicine side effects; D: Barriers. OCD: obsessivecompulsive disorder

self-reported reasons for NTRVs, the present study found that $30.1 \%$ of patients abandoned treatments because of medicine side effects (Table 4). In line with the findings of this study, reviews of Kampman [12] and Mitchell [26] also showed that the patient's choice of treatments was an essential factor influencing adherence. Given this finding and the substantial influence of side effects, we suggest a regular survey before the first visit about attitudes towards treatments, particularly pharmacotherapy, might be constructive for doctors to perform patient education.

Regarding the appraisal of illness severity, patients with higher SCL-90 subscale scores of somatization, anxiety, and phobic anxiety were more likely to complete TRVs (Table 2). The phobic anxiety subscale score was a protective factor for the NTRV (Table 3). A non-adherence study in patients with first-episode psychosis found that less severe positive symptoms at baseline could strongly predict poor medication adherence in the next one and two years [10]. This was similar in patients with depression [7]. These findings suggest that the perception and expectation of significant distress in the body or mind might push patients to carry out suitable initial adherence with less hesitation. Thus, more health education about normative medical intervention should be provided to mild-to-moderate-severity patients and their essential relatives.

This study also represented patients' balance between benefits and costs of return visits by analyzing the selfreported reasons for NTRVs. For example, patients transferred to other hospitals had higher ratios of "no improvement" (46.6\%) and "various barriers" (39.7\%) than other subgroups (Table 4). Similarly, being on the job was a risk factor for NTRVs (Table 3), perhaps because a return visit appointment would lead to loss of income. Subsequently, a study on treatment preferences in patients with depression showed that employed patients preferred psychotherapy over antidepressants [28], suggesting that patients on the job might be more afraid of medicine side effects influencing their functional status.

Many factors could influence the decision-making regarding a return visit. Social (including family atmosphere, living status, and residence) and personal factors (including age and personality) were relevant to initial adherence in the present study. A supportive family environment-for example, a happy family atmosphere or living with family members-did help improve initial adherence in this study, which was in line with many previous studies $[12,29,30]$. The influence of age on initial adherence was complex in the present study; there was a tendency of increasing TRVR with age while patients aged 26-35years old had the worst initial adherence with lower TRVR than those younger or older (Table 1). Consistent with our finding, a structural equation modeling study on adherence to psychopharmacological medications in psychiatric patients reported a weakly positive correlation between adherence and age [11]; in adult outpatients with depression, younger age was related to dropout at 12-week follow-up [30]. Usually, age was a background factor related to various psychological phenomena such as health belief, cognition pattern, social role conflict, and treatment experience and expectation. Therefore, we suspect there might be differing mediating factors between adherence and age in different study participants. Overall, younger adult psychiatric outpatients need more health education about initial adherence.

There were some limitations in this study. As the study was carried out in routine clinical practices, there could be uncontrollable, potentially confounding factors and a relatively high rate of follow-up failure. Although SCL-90 scores could reflect the severity to an extent, this study had not used specific instruments to assess it. Medicines prescribed in the first visit and patients' reactions might also be essential to the initial adherence, analyzed in another paper for complicated analyses and the length limitation. Additionally, factors related to doctor-patient communications could also influence 
initial adherence and should be determined in future research. The present study's findings should be cautiously generalized because of different medical environments among countries and districts. For example, there are apparent differences between healthcare payment policies and accessibility of health resources between China and European countries.

\section{Conclusions}

Poor initial adherence remained in psychiatric outpatients of the general hospital. Health education to patients, particularly younger and mild-severity patients, on the course of illness development, treatment methods, and the necessity of integrated case management are essential for working with psychiatric outpatients.

\section{Abbreviations}

IMA: Initial medication adherence; LTA: Long-term medication adherence; TRV: Timely return visit; NTRV: Non-timely return visit; TRVR: Timely return visit rate; EPQ: Eysenck Personality Questionnaire; SCL-90: Symptom checklist 90.

\section{Acknowledgments}

We thank Professor Nianhong Guan from the Third Affiliated Hospital of Sun Yat-sen University and Professor Chun Wang from The Affiliated Brain Hospital of Nanjing Medical University for their supports of this project.

\section{Authors' contributions}

XLW and MHC made the idea. XYW and MHC designed the study and monitored the process. LNZ, LY, GLL, LYL, MHC, and XLW carried out the study. XLW and $\mathrm{MHC}$ adapted the primary data. XLW completed the statistics. XLW, YLP, and $\mathrm{MHC}$ wrote the initial manuscript. XLW was in charge of the language edition of the manuscript and completed the submission. All authors read and approved the final manuscript.

\section{Funding}

This study was supported by Jiangsu Provincial Key Research and Development Program (BE2019609).

\section{Availability of data and materials}

The datasets used and analyzed during the current study are available from the corresponding author on reasonable request.

\section{Declarations}

\section{Ethics approval and consent to participate}

This study was approved by the Ethical Committee of The Affiliated Brain Hospital of Nanjing Medical University (2019-KY043-01). Informed consent was obtained from all participants.

\section{Consent for publication}

This manuscript does not contain data relating to any individual participants.

\section{Competing interests}

The authors declare that they have no competing interests.

\section{Author details}

${ }^{1}$ Department of Psychiatry, Third Affiliated Hospital of Sun Yat-sen University, N0. 600, Tianhe Road, Guangzhou 510630, China. ${ }^{2}$ Department of Psychiatry, Fifth Affiliated Hospital of Sun Yat-sen University, N0. 52, East Meihua Road, Zhuhai 519000, China.

Received: 27 September 2021 Accepted: 14 February 2022 Published online: 21 February 2022

\section{References}

1. Cramer JA, Roy A, Burrell A, Fairchild CJ, Fuldeore MJ, Ollendorf DA, et al. Medication compliance and persistence: terminology and definitions. Value Health. 2008;11(1):44-7.

2. Hutchins DS, Zeber JE, Roberts CS, Williams AF, Manias E, Peterson AM. Initial Medication Adherence-Review and Recommendations for Good Practices in Outcomes Research: An ISPOR Medication Adherence and Persistence Special Interest Group Report. Value Health. 2015;18(5):690-9.

3. Zeber JE, Manias E, Williams AF, Hutchins D, Udezi WA, Roberts CS, et al. A systematic literature review of psychosocial and behavioral factors associated with initial medication adherence: a report of the ISPOR medication adherence \& persistence special interest group. Value Health. 2013;16(5):891-900.

4. Chakrabarti S. What's in a name? Compliance, adherence and concordance in chronic psychiatric disorders. World J Psychiatry. 2014;4(2):30-6.

5. Chapman SC, Horne R. Medication non-adherence and psychiatry. Curr Opin Psychiatry. 2013;26(5):446-52.

6. Keller MB, Hirschfeld RM, Demyttenaere K, Baldwin DS. Optimizing outcomes in depression: focus on antidepressant compliance. Int Clin Psychopharmacol. 2002;17(6):265-71.

7. Buus N, Johannessen H, Stage KB. Explanatory models of depression and treatment adherence to antidepressant medication: a qualitative interview study. Int J Nurs Stud. 2012;49(10):1220-9.

8. Ibironke Thomas F, Osasu Olotu S, Ohiole OJ. Prevalence, factors and reasons associated with missed first appointments among out-patients with schizophrenia at the Federal Neuro-Psychiatric Hospital, Benin City BJPsych Open. 2018;4(2):49-54.

9. Greene M, Paladini L, Lemmer T, Piedade A, Touya M, Clark O. Systematic literature review on patterns of pharmacological treatment and adherence among patients with bipolar disorder type I in the USA. Neuropsychiatr Dis Treat. 2018;14:1545-59.

10. Lai-Ming Hui C, Wing-Yan Poon V, Shuk-Kuen Kwok V, Chang WC, Kit-Wa Chan S, Ho-Ming Lee E, et al. Prevalence and predictors of medication non-adherence among Chinese patients with first-episode psychosis. Psychiatry Res. 2015;228(3):680-7.

11. De Las CC, de Leon J, Penate W, Betancort M. Factors influencing adherence to psychopharmacological medications in psychiatric patients: a structural equation modeling approach. Patient Prefer Adherence. 2017;11:681-90.

12. Kampman O, Lehtinen K. Compliance in psychoses. Acta Psychiatr Scand. 1999;100(3):167-75.

13. Kamei K, Terao T, Katayama Y, Hoaki N. Affective temperaments and psychotropic adherence. J Affect Disord. 2013;150(3):1142-7.

14. Wouters H, Amin DF, Taxis K, Heerdink ER, Egberts AC, Gardarsdottir $H$. Associations Between Personality Traits and Adherence to Antidepressants Assessed Through Self-Report, Electronic Monitoring, and Pharmacy Dispensing Data: A Pilot Study. J Clin Psychopharmacol. 2016;36(5):465-71.

15. World Medical Association Declaration of Helsinki. ethical principles for medical research involving human subjects. JAMA. 2013;310(20):2191-4.

16. Gong Y. Use of the Eysenck Personality Questionnaire in China. Personal Individ Differ. 1984;5(4):431-8.

17. Eysenck HJ, Eysenck SBG. Manual of the Eysenck Personality Questionnaire (junior \& adult): Hodder and Stoughton Educational; 1975.

18. Wang Z. SCL-90. Shanghai. Psychiatry. 1984:68-70.

19. Jin H, Wu W, Zhang M. Preliminary analysis of SCL-90 evaluation results in Chinese normal adults. Chinese J Nervus Mental Dis. 1986;12:260-3.

20. Derogatis LR, Lipman RS, Covi L. SCL-90. an outpatient psychiatric rating scale--preliminary report. Psychopharmacol Bull. 1973;9(1):13-28.

21. Duffy R, B DK. Adherence in psychiatry. Ir. J Psychol Med. 2010;27(1):i-vii.

22. Olfson M, Mojtabai R, Sampson NA, Hwang I, Druss B, Wang PS, et al. Dropout from outpatient mental health care in the United States. Psychiatr Serv. 2009;60(7):898-907.

23. Loots E, Goossens E, Vanwesemael T, Morrens M, Van Rompaey B, Dilles T. Interventions to Improve Medication Adherence in Patients with Schizophrenia or Bipolar Disorders: A Systematic Review and Meta-Analysis. Int J Environ Res Public Health. 2021;18:10213.

24. Yau WY, Chan MC, Wing YK, Lam HB, Lin W, Lam SP, et al. Noncontinuous use of antidepressant in adults with major depressive disorders - a retrospective cohort study. Brain Behav. 2014;4(3):390-7. 
25. Gu S, Wei Q, Guo J, Jie N. Influencing factors of medication compliance of outpatients with first episode depression in a general hospital. J Third Military Med Univ. 2014;36(11):1121-4.

26. Mitchell AJ. Adherence behaviour with psychotropic medication is a form of self-medication. Med Hypotheses. 2007;68(1):12-21.

27. Berk M, Berk L, Castle D. A collaborative approach to the treatment alliance in bipolar disorder. Bipolar Disord. 2004;6(6):504-18.

28. Houle J, Villaggi B, Beaulieu MD, Lespérance F, Rondeau G, Lambert J. Treatment preferences in patients with first episode depression. J Affect Disord. 2013;147(1-3):94-100.

29. Kardas P, Lewek P, Matyjaszczyk M. Determinants of patient adherence: a review of systematic reviews. Front Pharmacol. 2013;4:91.

30. Zhang J, Ye C. Factors associated with loss to follow-up of outpatients with depression in general hospitals. J Int Med Res. 2020;48(5):1-9.

\section{Publisher's Note}

Springer Nature remains neutral with regard to jurisdictional claims in published maps and institutional affiliations.

- fast, convenient online submission

- thorough peer review by experienced researchers in your field

- rapid publication on acceptance

- support for research data, including large and complex data types

- gold Open Access which fosters wider collaboration and increased citations

- maximum visibility for your research: over $100 \mathrm{M}$ website views per year

At BMC, research is always in progress.

Learn more biomedcentral.com/submissions 